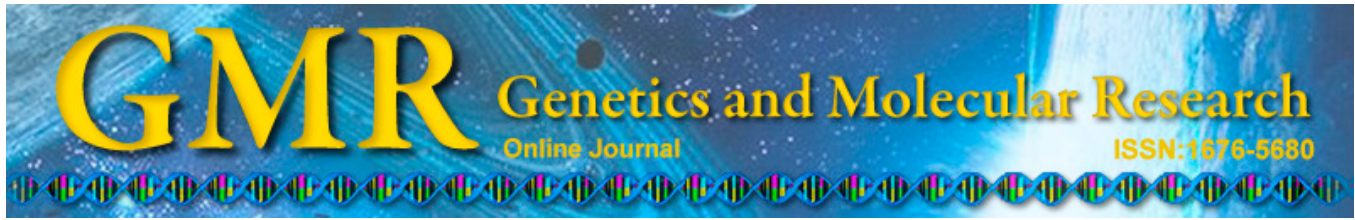

\title{
Epidemiological analysis of pneumoconiosis in the Xinjiang Uygur Autonomous Region and cases reported by the Urumqi Railway Bureau
}

\author{
G.T. Liu ${ }^{1,2}$, X.J. Li ${ }^{3}$, Y.H. Wei ${ }^{1}$, W.L. Wei ${ }^{1}$, X.H. Wang ${ }^{1}$, H. Yuan ${ }^{2}$ \\ and $H$. Wufuer ${ }^{1}$ \\ ${ }^{1}$ Xinjiang Medical University, Urumqi, Xinjiang, China \\ ${ }^{2}$ Department of Occupational Disease Prevention and Control, \\ Fifth Affiliated Hospital of Xinjiang Medical University, Urumqi, \\ Xinjiang, China \\ ${ }^{3}$ Basis College, Xinjiang Medical University, Urumqi, Xinjiang, China \\ Corresponding author: H. Wufuer \\ E-mail: HamulatiWufuer@163.com
}

Genet. Mol. Res. 14 (1): 1612-1623 (2015)

Received January 27, 2014

Accepted April 16, 2014

Published March 6, 2015

DOI http://dx.doi.org/10.4238/2015.March.6.8

\begin{abstract}
This study investigated the incidence and development of pneumoconiosis in the Xinjiang Uygur Autonomous Region and cases reported by the Urumqi Railway Bureau to provide a scientific basis for developing prevention and control measures against pneumoconiosis. Data from pneumoconiosis cases were input into Excel and analyzed by SPSS version 17.0. There were 13,165 cases of pneumoconiosis through 2010. Coal workers accounted for the largest proportion of cases. From July 2006 through 2010, a total of 1233 new cases of pneumoconiosis were reported in the Xinjiang Uygur Autonomous Region; most cases were reported in Urumqi. From 1981 to 2012, 3332 new cases of pneumoconiosis had been confirmed by the Urumqi Railway Bureau, including $77.73,16.96$, and $5.31 \%$ stage I, II, and III cases, respectively.
\end{abstract}


In the last 30 years, the number of new pneumoconiosis cases peaked in 1986; most of them were silicosis cases. In addition, there were more than 200 cases of pneumoconiosis combined with pulmonary tuberculosis reported by the Urumqi Railway Bureau. The coal industry in Urumqi is the main industry in which occupational pneumoconiosis occurs in Xinjiang. Thus, substantial effort is still required to eliminate pneumoconiosis by 2030 .

Key words: Pneumoconiosis; Epidemiological survey

\section{INTRODUCTION}

Pneumoconiosis is a systemic disease resulting from various professional activities. It mainly manifests as diffuse fibrosis of the lung tissues as a result of the long-term inhalation and retention of dust in the lungs. At present, several domestic and foreign epidemiological studies on pneumoconiosis indicate that pneumoconiosis is the most important occupational disease worldwide. There are also several epidemiological studies about the complications related to pneumoconiosis; the results indicate that patients with pneumoconiosis are a high-risk population for tuberculosis, with a combined incidence rate of 10-30\% (Hnizdo and Vallyathan, 2003). In addition, the combination of pneumoconiosis with pulmonary tuberculosis results in a higher mortality rate (Nasrullah et al., 2011). Obviously, the prevention of pneumoconiosis is a global health problem. Accordingly, the global epidemiological situation of pneumoconiosis must be understood in order to develop an effective control strategy. Although many epidemiological studies of pneumoconiosis (e.g., Seaton et al., 1991; Linch et al., 1998; Kauppinen et al., 2000; Rosenman et al., 2003; Saiyed and Tiwari, 2004; Soutar et al., 2004; Carneiro et al., 2006; Smith and Leggat, 2006; Bang et al., 2008; Madl et al., 2008; Mazurek and Attfield, 2008; Choi et al., 2010; Laney et al., 2010; Nelson et al., 2010; Suarthana et al., 2011; Nelson, 2013), more than 20 articles about the epidemiological analysis of pneumoconiosis in domestic provinces and cities (e.g., Li et al., 2010; Courtice et al., 2012; Zhang et al., 2013; Mo et al., 2014), and 1 article from Changji, Xinjiang (Wang and Wang, 2010) have been published in the last 5 years, there have been no reports about the epidemiological analysis of pneumoconiosis in the Xinjiang Uygur Autonomous Region or by the Urumqi Railway Bureau. Accordingly, to understand the epidemiological characteristics and dynamic changes of new cases of pneumoconiosis in Xinjiang in recent years, this epidemiological study investigated pneumoconiosis cases before June 2006 and from July 2006 through 2010 in the Xinjiang Uygur Autonomous Region as well as cases reported by the Urumqi Railway Bureau from 1981 to 2012. The data were classified, summarized, and analyzed to better understand the incidence, development, turnover, and prognosis of pneumoconiosis in Xinjiang, to evaluate the effects of pneumoconiosis control, and to develop scientifically based preventive strategies for pneumoconiosis.

\section{MATERIAL AND METHODS}

\section{Data source}

The data of pneumoconiosis cases before June 2006 and from July 2006 through 2010 in the Xinjiang Uygur Autonomous Region were obtained from the Information System-Pneu- 
moconiosis Reporting Database of the Center of Disease Control of the Xinjiang Uygur Autonomous Region (data were provided by professionals in the Vocational Division). The data and clinical information of new cases of pneumoconiosis from the Urumqi Railway Bureau from 1981 to 2012 were obtained from the Occupational Disease Prevention Section of the Fifth Affiliated Hospital of Xinjiang Medical University.

\section{Analysis}

The abovementioned data were input into Excel, and classified, summarized, and analyzed by SPSS version 17.0.

\section{RESULTS}

\section{Pneumoconiosis cases in Xinjiang}

Until June 2006 and from July 2006 through 2010, 11,932 and 13,165 cases of pneumoconiosis were reported in the Xinjiang Uygur Autonomous Region, respectively (Table 1). At the end of 2010, among the 13 kinds of pneumoconiosis classifications, the largest proportion of ongoing cases was coal worker's pneumoconiosis (CWP), accounting for 5476 cases (41.59\%), followed by 4727 (35.90\%), 1050 (7.98\%), $302(2.29 \%), 288(2.19 \%)$, and 406 $(3.08 \%)$ cases of silicosis, cement pneumoconiosis (CP), electric welder's pneumoconiosis (EWP), foundry worker's pneumoconiosis (FWP), and asbestosis pneumoconiosis, respectively. The proportions of other types of pneumoconiosis were relatively small (Table 1).

\begin{tabular}{|c|c|c|c|}
\hline Disease classification & Cases until June 2006 & Cases through 2010 & Ongoing percentage $(\%)$ \\
\hline Total & 11,932 & 13,165 & 100 \\
\hline Silicosis & 4,387 & 4,727 & 35.90 \\
\hline Coal worker's pneumoconiosis & 4,950 & 5,476 & 41.59 \\
\hline Graphite pneumoconiosis & 26 & 26 & 0.20 \\
\hline Carbon black pneumoconiosis & 28 & 30 & 0.22 \\
\hline Asbestosis & 404 & 406 & 3.08 \\
\hline Talc pneumoconiosis & 4 & 4 & 0.02 \\
\hline Cement pneumoconiosis & 763 & 1,050 & 7.98 \\
\hline Mica pneumoconiosis & 32 & 33 & 0.25 \\
\hline Potter's pneumoconiosis & 76 & 81 & 0.62 \\
\hline Aluminum pneumoconiosis & 8 & 9 & 0.06 \\
\hline Electric welder's pneumoconiosis & 266 & 302 & 2.29 \\
\hline Foundry worker's pneumoconiosis & 276 & 288 & 2.19 \\
\hline Other pneumoconiosis & 712 & 733 & 5.57 \\
\hline
\end{tabular}

From July 2006 through 2010, a total of 1233 new cases of pneumoconiosis were reported in the Xinjiang Uygur Autonomous Region, including 340 cases of silicosis (27.58\%), 526 cases of CWP (42.66\%), 287 cases of CP (23.28\%), 36 cases of EWP (2.92\%), and 12 cases of FWP $(0.97 \%)$. From July 2006, the average annual occurrence rate of pneumoconiosis was about 274 cases, including 76, 117, 63.78, 8, and 2.67 new cases of silicosis, CWP, CP, EWP, and FWP, respectively (Table 2).

Considering the 2010 data, 284 new cases were reported from various medical institutions and diagnostic agencies, with 34 cases in a deteriorative situation; 154 cases were reported in Urumqi, including 123 new cases and 31 cases in a deteriorative situation, ac- 


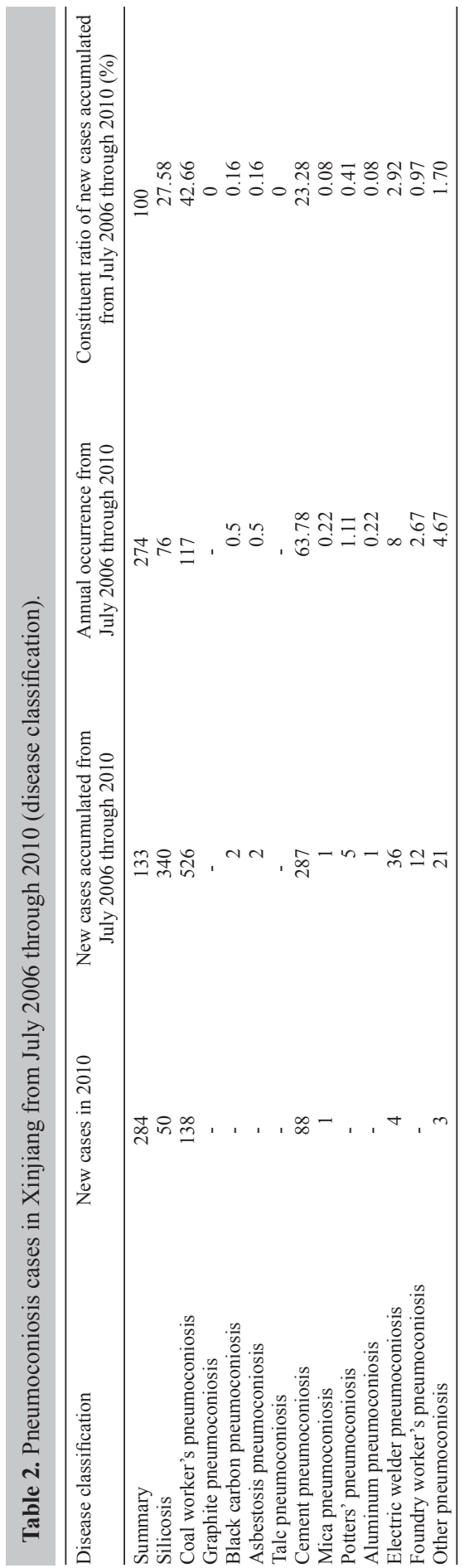


counting for $48.43 \%$. In the Kashi region, 93 cases were reported, accounting for $29.25 \%$. In Changji Hui Autonomous Prefecture, 22 cases were reported, including 21 new cases and 1 case in a deteriorative situation, accounting for $6.92 \%$. In Ili Kazak Autonomous Prefecture, 15 cases were reported, including 14 new cases and 1 case in a deteriorative situation, accounting for $4.72 \%$. In the Hami region, 11 new cases were reported, accounting for $3.46 \%$. In the Aksu region, 11 cases were reported, accounting for $3.46 \%$. In the Altay region, 5 cases were reported, accounting for $1.57 \%$. In Karamay City, 4 new cases were reported, accounting for $1.26 \%$. In addition, small numbers of cases were reported in other regions (Table 3 ).

\begin{tabular}{|c|c|c|c|c|c|c|c|c|c|c|}
\hline \multirow[t]{2}{*}{ Region } & \multirow[t]{2}{*}{ Summary } & \multirow{2}{*}{$\begin{array}{l}\text { Constituent } \\
\text { ratio }(\%)\end{array}$} & \multicolumn{4}{|c|}{ New cases } & \multicolumn{4}{|c|}{ Cases in a deteriorative situation } \\
\hline & & & Sub-summary & $\begin{array}{l}\text { Medical } \\
\text { institution }\end{array}$ & $\begin{array}{l}\text { Diagnostic } \\
\text { agency }\end{array}$ & Others & Sub-summary & $\begin{array}{l}\text { Medical } \\
\text { institution }\end{array}$ & $\begin{array}{l}\text { Diagnostic } \\
\text { agency }\end{array}$ & Others \\
\hline Total & 318 & 100 & 284 & 171 & 113 & - & 34 & 32 & 2 & - \\
\hline Urumqi & 154 & 48.43 & 123 & 106 & 17 & - & 31 & 30 & 1 & - \\
\hline Karat & 4 & 1.26 & 4 & 2 & 2 & - & - & - & - & - \\
\hline Turfan & - & - & - & - & - & - & - & - & - & - \\
\hline Hami & 11 & 3.46 & 11 & 11 & - & - & - & - & - & - \\
\hline Changji Hui Autonomous Prefecture & 22 & 6.92 & 21 & 21 & - & - & 1 & 1 & - & - \\
\hline $\begin{array}{l}\text { Bortala Mongol } \\
\text { Autonomous Prefecture }\end{array}$ & - & - & - & - & - & - & - & - & - & - \\
\hline $\begin{array}{l}\text { Bayingolin Mongol } \\
\text { Autonomous Prefecture }\end{array}$ & 1 & 0.31 & - & - & - & - & 1 & - & 1 & - \\
\hline Aksu & 11 & 3.46 & 11 & 11 & - & - & - & - & - & - \\
\hline Kizilsu Kirghiz Autonomous Prefecture & - & - & - & - & - & - & - & - & - & - \\
\hline Kasha & 93 & 29.25 & 93 & - & 93 & - & - & - & - & - \\
\hline Hotan & - & - & - & - & - & - & - & - & - & - \\
\hline Ili Kazak Autonomous Prefecture & 15 & 4.72 & 14 & 14 & - & - & 1 & 1 & - & - \\
\hline Tuscaloosa & 1 & 0.31 & 1 & 1 & - & - & - & - & - & - \\
\hline Altay & 5 & 1.57 & 5 & 5 & - & - & - & - & - & - \\
\hline $\begin{array}{l}\text { County-level administrative units } \\
\text { in the autonomous region }\end{array}$ & - & - & - & - & - & - & - & - & - & - \\
\hline Others & 1 & 0.31 & 1 & - & 1 & - & - & - & - & \\
\hline
\end{tabular}

From July 2006 through 2010, a total of 1233 pneumoconiosis cases were reported in people with various occupations. The coal industry reported the most cases - 469 cases (38.04\%) - followed by the building materials industry $(312,25.30 \%)$, non-ferrous metals industry $(134,10.87 \%)$, railway industry $(60,4.87 \%)$, electricity industry $(29,2.35 \%)$, metallurgical industry $(48,3.89 \%)$, construction industry $(55,4.46 \%)$, chemical industry $(27,2.19 \%)$, telecommunications industry $(14,1.14 \%)$, machinery industry $(12,0.97 \%)$, light industry $(19$, $1.54 \%)$, geological mining industry $(11,0.89 \%)$, and transport industry $(8,0.65 \%)$. Other industries reported very few cases (Table 4).

\section{Epidemiological analysis of pneumoconiosis cases reported by the Urumqi Railway Bureau (1981-2012)}

\section{Basic information}

From 1981 to 2012, there were 3332 new cases of pneumoconiosis confirmed by the Urumqi Railway Bureau, including 3317 cases in men and 15 in women (male/female ratio: 
221:1). The average annual number of new cases was 104 cases. The patients were aged 36-81 years, with a mean age of 56 years. The period of service among pneumoconiosis cases ranged from 1 to 28 years, with a mean of 10 years. Among the newly diagnosed cases in all 32 years, $2590(77.73 \%), 565(16.96 \%)$, and 177 (5.31\%) were stage I, II, and III cases, respectively (Table 5).

Table 4. Occurrence of 13 types of pneumoconiosis in Xinjiang from July 2006 through 2010 (by industry).

\begin{tabular}{|c|c|c|c|c|c|c|c|c|c|c|c|c|c|c|c|}
\hline Industry & Total & Constituent ratio (\%) & Silicosis & CWP & GP & CBP & AP & $\mathrm{TP}$ & $\mathrm{CP}$ & MP & PP & $\mathrm{AP}$ & EWP & FWP & Others \\
\hline Total & 133 & 100 & 340 & 526 & - & 2 & 2 & - & 287 & 1 & 5 & 1 & 36 & 12 & 21 \\
\hline Coal & 469 & 38.04 & 22 & 445 & - & - & - & - & - & - & - & - & 2 & - & - \\
\hline Oil & 2 & 0.16 & 2 & - & - & - & - & - & - & - & - & - & - & - & - \\
\hline Electricity & 29 & 2.35 & 2 & 24 & - & - & - & - & - & - & - & - & 3 & - & - \\
\hline Nuclear & - & - & - & - & - & - & - & - & - & - & - & - & - & - & - \\
\hline Metallurgy & 48 & 3.89 & 39 & 5 & - & 2 & - & - & 1 & - & - & - & - & 1 & - \\
\hline Non-ferrous metal & 134 & 10.87 & 125 & 3 & - & - & - & - & - & 1 & 1 & 1 & 3 & - & - \\
\hline Machinery & 12 & 0.97 & 4 & 1 & - & - & - & - & - & - & - & - & 6 & 1 & - \\
\hline Electron & - & - & - & - & - & - & - & - & - & - & - & - & - & - & - \\
\hline Weapons & - & - & - & - & - & - & - & - & - & - & - & - & - & - & - \\
\hline Ships & - & - & - & - & - & - & - & - & - & - & - & - & - & - & - \\
\hline Chemical engineering & 27 & 2.19 & 4 & 20 & - & - & - & - & - & - & - & - & 3 & - & - \\
\hline Medicine & - & - & - & - & - & - & - & - & - & - & - & - & - & - & - \\
\hline Railway & 60 & 4.87 & 48 & 7 & - & - & - & - & 2 & - & - & - & 3 & - & - \\
\hline Transportation & 8 & 0.65 & 6 & 1 & - & - & - & - & 1 & - & - & - & - & - & - \\
\hline Building materials & 312 & 25.30 & 25 & 2 & - & - & 2 & - & 280 & - & - & - & 3 & - & - \\
\hline Construction & 55 & 4.46 & 32 & 7 & - & - & - & - & 3 & - & - & - & 7 & 3 & 3 \\
\hline Geological mining & 11 & 0.89 & 8 & 2 & - & - & - & - & - & - & - & - & 1 & - & - \\
\hline Water resources & 3 & 0.24 & 1 & 2 & - & - & - & - & - & - & - & - & - & - & - \\
\hline Agriculture & 5 & 0.41 & - & - & - & - & - & - & - & - & - & - & - & - & 5 \\
\hline Forest & 1 & 0.08 & - & - & - & - & - & - & - & - & - & - & - & - & 1 \\
\hline Light industry & 19 & 1.54 & 6 & 1 & - & - & - & - & - & - & - & - & 2 & 3 & 7 \\
\hline Weaving & 3 & 0.24 & - & - & - & - & - & - & - & - & - & - & 2 & - & 1 \\
\hline Aviation and spaceflight & - & - & - & - & - & - & - & - & - & - & - & - & - & - & - \\
\hline Business & 6 & 0.49 & 1 & 2 & - & - & - & - & - & - & 1 & - & - & - & 2 \\
\hline Postal and telecommunications & 14 & 1.14 & 14 & - & - & - & - & - & - & - & - & - & - & - & - \\
\hline Petrifaction & - & - & - & - & - & - & - & - & - & - & - & - & - & - & - \\
\hline Recycling and processing & - & - & - & - & - & - & - & - & - & - & - & - & - & - & - \\
\hline Others & 15 & 1.22 & 1 & 4 & - & - & - & - & - & - & 3 & - & 1 & 4 & 2 \\
\hline
\end{tabular}

$\mathrm{CWP}=$ coal worker's pneumoconiosis; $\mathrm{GP}=$ graphite pneumoconiosis; $\mathrm{CBP}=$ carbon black pneumoconiosis; $\mathrm{AP}=$ asbestosis pneumoconiosis; $\mathrm{TP}=$ talc pneumoconiosis; $\mathrm{CP}=$ cement pneumoconiosis; $\mathrm{MP}=$ mica pneumoconiosis; $\mathrm{PP}=$ Potters' pneumoconiosis; $\mathrm{AP}=$ aluminum pneumoconiosis; $\mathrm{EWP}=$ electric welder pneumoconiosis; $\mathrm{FWP}=$ foundry worker's pneumoconiosis.

\section{Disease distribution}

Among the new cases of pneumoconiosis confirmed by the Urumqi Railway Bureau from 1981 to 2012, an overwhelming majority of cases were silicosis, accounting for $91.09 \%$, followed by CP, CWP, EWP, and FWP, accounting for $2.25,1.81,1.12$, and $0.43 \%$ of new cases, respectively. Asbestosis and mica pneumoconiosis were rare, while no cases of other types of pneumoconiosis were recorded (Table 6).

\section{Occupational distribution}

Among the 3332 new cases of pneumoconiosis reported by the Urumqi Railway Bureau from 1981 to 2012, the overwhelming majority of cases occurred in mountain workers (2988 cases, 89.68\%), followed by cement, coal, electricity, and foundry workers (Table 7). 


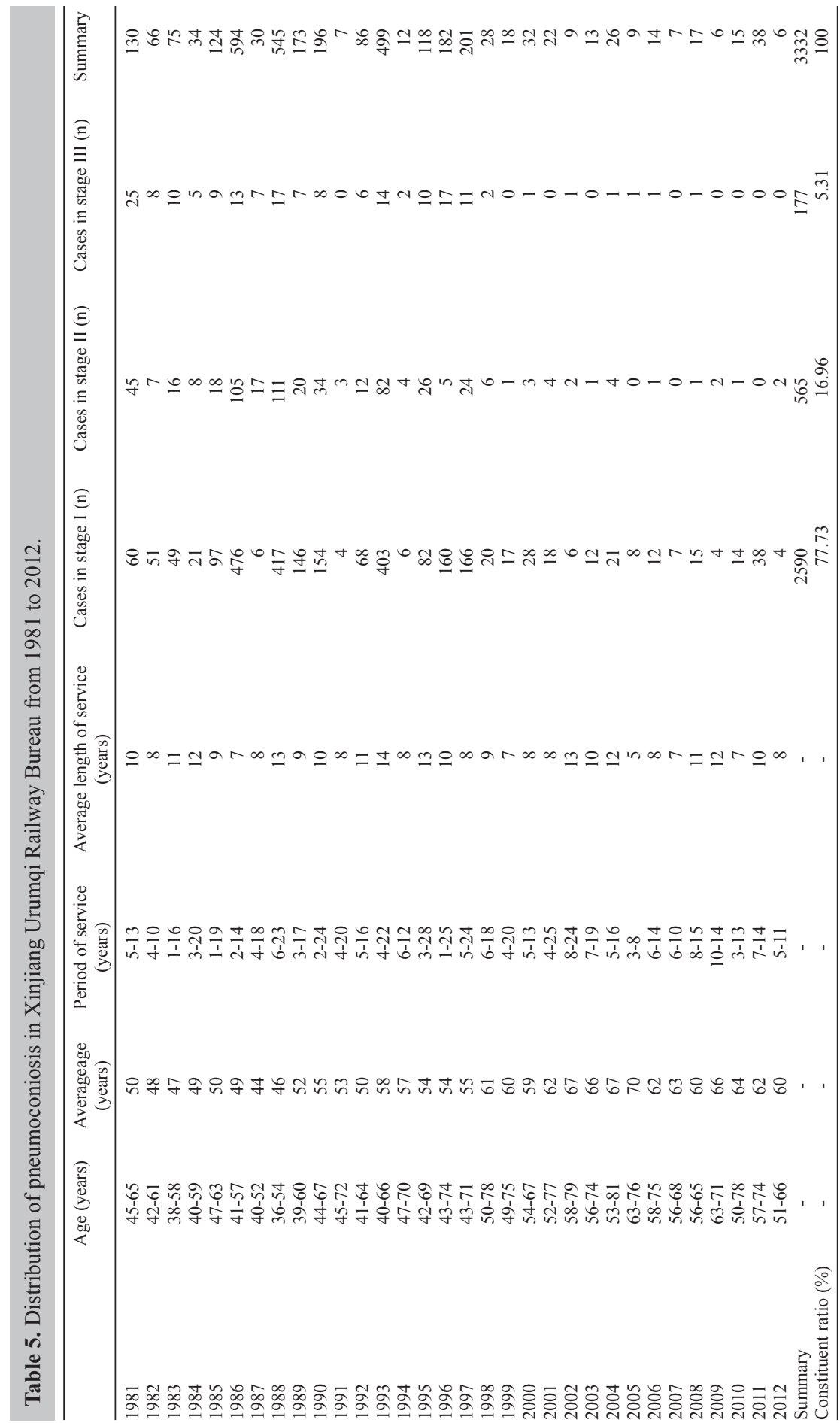


Table 6. Distribution of pneumoconiosis cases reported by the Xinjiang Urumqi Railway Bureau from 1981 to 2012.

\begin{tabular}{|c|c|c|c|c|c|c|c|c|c|c|c|c|c|c|}
\hline & Silicosis & CWP & $\mathrm{CP}$ & EWP & FWP & GP & CBP & $\mathrm{AP}$ & $\mathrm{TP}$ & MP & $\mathrm{AP}$ & PP & Others & Total \\
\hline 1981 & 123 & - & - & 1 & - & - & - & - & - & - & - & - & 6 & 130 \\
\hline 1982 & 64 & - & 1 & - & - & - & - & - & - & - & - & - & 1 & 66 \\
\hline 1983 & 67 & - & - & 2 & - & - & - & - & - & - & - & - & 6 & 75 \\
\hline 1984 & 29 & 3 & 1 & 1 & - & - & - & - & - & - & - & - & - & 34 \\
\hline 1985 & 114 & - & - & 5 & - & - & - & - & - & - & - & - & 5 & 124 \\
\hline 1986 & 583 & 2 & 9 & - & - & - & - & - & - & - & - & - & & 594 \\
\hline 1987 & 28 & - & - & - & - & - & - & - & - & - & - & - & 2 & 30 \\
\hline 1988 & 484 & 8 & 15 & 1 & 3 & - & - & - & - & - & - & - & 34 & 545 \\
\hline 1989 & 152 & - & 3 & 5 & - & - & - & - & - & - & - & - & 13 & 173 \\
\hline 1990 & 164 & - & 4 & 6 & 1 & - & - & - & - & - & - & - & 21 & 196 \\
\hline 1991 & 7 & - & - & - & - & - & - & - & - & - & - & - & & 7 \\
\hline 1992 & 81 & 1 & - & 2 & - & - & - & - & - & - & - & - & 2 & 86 \\
\hline 1993 & 491 & 1 & 2 & 4 & 1 & - & - & - & - & - & - & - & - & 499 \\
\hline 1994 & 11 & - & - & 1 & - & - & - & - & - & - & - & - & - & 12 \\
\hline 1995 & 110 & 4 & 4 & - & - & - & - & - & - & - & - & - & - & 118 \\
\hline 1996 & 169 & 8 & 4 & - & - & - & - & - & - & - & - & - & 1 & 182 \\
\hline 1997 & 153 & 9 & 18 & 3 & 8 & - & - & - & - & 1 & - & - & 9 & 201 \\
\hline 1998 & 23 & 2 & - & - & - & - & - & - & - & - & - & - & 3 & 28 \\
\hline 1999 & 17 & - & 1 & - & - & - & - & - & - & - & - & - & - & 18 \\
\hline 2000 & 28 & 1 & 1 & 2 & - & - & - & - & - & - & - & - & - & 32 \\
\hline 2001 & 19 & - & 2 & 1 & - & - & - & - & - & - & - & - & - & 22 \\
\hline 2002 & 9 & - & - & - & - & - & - & - & - & - & - & - & - & 9 \\
\hline 2003 & 10 & 1 & 1 & - & - & - & - & - & - & - & - & - & 1 & 13 \\
\hline 2004 & 21 & 2 & 2 & - & - & - & - & - & - & - & - & - & 1 & 26 \\
\hline 2005 & 5 & 2 & - & - & - & - & - & - & - & - & - & - & 2 & 9 \\
\hline 2006 & 9 & - & 1 & 3 & - & - & - & - & - & - & - & - & 1 & 14 \\
\hline 2007 & 4 & 1 & 1 & - & - & - & - & - & - & - & - & - & 1 & 7 \\
\hline 2008 & 14 & 1 & 1 & - & 1 & - & - & - & - & - & - & - & - & 17 \\
\hline 2009 & 5 & 1 & - & - & - & - & - & - & - & - & - & - & - & 6 \\
\hline 2010 & 5 & 8 & 1 & - & - & - & - & - & - & - & - & - & 1 & 15 \\
\hline 2011 & 30 & 5 & 3 & - & - & - & - & - & - & - & - & - & - & 38 \\
\hline 2012 & 6 & - & - & - & - & - & - & - & - & - & - & - & - & 6 \\
\hline Total & 3035 & 60 & 75 & 37 & 14 & - & - & - & - & 1 & - & - & 110 & 3332 \\
\hline Constituent ratio (\%) & 91.09 & 1.81 & 2.25 & 1.12 & 0.43 & - & - & - & - & - & - & - & 3.3 & 100 \\
\hline
\end{tabular}

$\mathrm{CWP}=$ coal worker's pneumoconiosis; $\mathrm{CP}=$ cement pneumoconiosis; $\mathrm{EWP}=$ electric welder pneumoconiosis; $\mathrm{FWP}=$ foundry worker's pneumoconiosis; GP = graphite pneumoconiosis; $\mathrm{CBP}=$ carbon black pneumoconiosis; $\mathrm{AP}=$ asbestosis pneumoconiosis; $\mathrm{TP}=$ talc pneumoconiosis; $\mathrm{MP}=$ mica pneumoconiosis; $\mathrm{AP}=$ aluminum pneumoconiosis; $\mathrm{PP}=$ Potters' pneumoconiosis.

\section{Temporal distribution}

Among the new cases reported by the Urumqi Railway Bureau from 1981 to 2012, new cases peaked in 1986 followed by 1988 and 1993, decreasing after 1998 to the minimum in 2009 and 2012 (Table 5).

\section{Combination pneumoconiosis with pulmonary tuberculosis}

From 1981 to 2012, among the new cases of pneumoconiosis, there were 226 cases combined with pulmonary tuberculosis; among them, 87, 38, and 101 cases were diagnosed as active pulmonary tuberculosis, suspected tuberculosis, and old tuberculosis, respectively. The number of combined cases peaked in 1986, with 41 cases, decreasing thereafter, and slightly peaking again in 2012 . 
Table 7. Types of pneumoconiosis by job type reported by theUrumqi Railway Bureau from1981 to 2012.

\begin{tabular}{lcccccccccccccr}
\hline & Silicosis & CWP & CP & EWP & FWP & GP & CBP & AP & TP & MP & AP & PP & Others & Total \\
\hline Mountain work & 2988 & - & - & - & - & - & - & - & - & - & - & - & - & 2988 \\
Cementer & - & - & 63 & - & - & - & - & - & - & - & - & - & - & 63 \\
Quarryman & 8 & - & - & - & - & - & - & - & - & - & - & - & - & 8 \\
Coal worker & - & 46 & - & - & - & - & - & - & - & - & - & - & - & 46 \\
Rockdrilling & 5 & - & - & - & - & - & - & - & - & - & - & - & - & 5 \\
Tunneling & 21 & - & - & - & - & - & - & - & - & - & - & - & - & 21 \\
Coal-feeding & - & 6 & - & - & - & - & - & - & - & - & - & - & - & 6 \\
Sandcasting & 1 & - & - & - & - & - & - & - & - & - & - & - & - & 1 \\
Concrete working & - & - & 11 & - & - & - & - & - & - & - & - & - & - & 11 \\
Stonemasonry & - & - & - & - & - & - & - & - & - & - & - & - & - & - \\
Stevedore & 2 & 7 & 1 & - & - & - & - & - & - & - & - & - & - & 10 \\
Electrical & 6 & - & - & 30 & & - & - & - & - & - & - & - & - & 36 \\
Heat sealing & - & - & - & - & 2 & - & - & - & - & - & - & - & - & 2 \\
Digging & - & 1 & - & - & - & - & - & - & - & - & - & - & - & 1 \\
Foundry & - & - & - & - & 11 & - & - & - & - & - & - & - & - & 11 \\
Circuitry & - & - & - & - & - & - & - & - & - & - & - & - & - & - \\
Supporting worker & 1 & - & - & - & - & - & - & - & - & - & - & - & - & 1 \\
Others & 3 & - & - & 7 & 1 & - & - & - & - & 1 & - & - & 110 & 122 \\
Total & 3035 & 60 & 75 & 37 & 14 & - & - & - & - & 1 & - & - & 110 & 3332 \\
\hline
\end{tabular}

$\mathrm{CWP}=$ coal worker's pneumoconiosis; $\mathrm{CP}=$ cement pneumoconiosis; $\mathrm{EWP}=$ electric welder pneumoconiosis; $\mathrm{FWP}=$ foundry worker's pneumoconiosis; $\mathrm{GP}=$ graphite pneumoconiosis; $\mathrm{CBP}=$ carbon black pneumoconiosis; $\mathrm{AP}=$ asbestosis pneumoconiosis; $\mathrm{TP}=$ talc pneumoconiosis; $\mathrm{MP}=$ mica pneumoconiosis; $\mathrm{AP}=$ aluminum pneumoconiosis; PP = Potters' pneumoconiosis.

\section{Pneumoconiosis cases combined with pleural effusion}

There were 28 cases of pneumoconiosis combined with pleural effusion from 2007 to 2012, including 23 and 5 cases involving transudate and exudate, respectively. After the antituberculosis treatment, 11 cases achieved good results, 3 cases experienced recurrence, and 1 case was invalid.

\section{DISCUSSION}

\section{Epidemiological investigation of pneumoconiosis in Xinjiang by occupation}

$\mathrm{Ou}$ (2011) reported that from the 1950s through 2010, there were 749,970 cumulative cases of occupational diseases reported in China; this includes 676,541 cases of pneumoconiosis, which include 149,110 and 527,431 fatal and living cases, respectively. There were 10 categories of occupations, with a total of 115 diseases including pneumoconiosis, occupational radiation sickness, and occupational poisoning. In Xinjiang, the incidence of pneumoconiosis is much higher than those of other kinds of occupational diseases. Through 2010, there were 13,165 cases of pneumoconiosis in Xinjiang. Among the 13 kinds of pneumoconiosis, CWP accounted for the largest proportion followed by silicosis. From July 2006 through 2010, a total of 1233 new cases of pneumoconiosis were reported in the Xinjiang Uygur Autonomous Region. Among the 14 municipalities and regions of the Xinjiang Uygur Autonomous Region, the largest proportion was reported in Urumqi (154 cases), followed by Kashi, Changji Hui Autonomous Prefecture, Ili Kazak Autonomous Prefecture, Hami, Aksu, Altay, Karamay, and so on. Regarding the situations of individual industries, the coal industry reported the most number of cases $(469,38.04 \%)$, followed by the building materials industry; other industries 
also reported several cases, including the non-ferrous metal, railway, power, metallurgical, construction, chemical, telecommunications industry, machinery, light, and geological mining industries. In recent years, efforts to eliminate occupational pneumoconiosis in Urumqi have focused on the coal industry. However, the present results indicate that other areas and industries should also be strictly regulated. As a large country with a high incidence of occupational diseases, China has taken up the goal of the global elimination of pneumoconiosis by 2030 initiated by the International Labour Organization and World Health Organization. However, the present results show that there is still a long way to go.

\section{Epidemiological investigation of occupational pneumoconiosis reported by the Urumqi Railway Bureau}

There were 3332 newly diagnosed cases of pneumoconiosis reported by the Urumqi Railway Bureau from 1981 to 2012; the overwhelming majority of cases were in men. Moreover, there were 2590 (77.73\%), 565 (16.96\%), and 177 (5.31\%) cases in stage I, II, and III, respectively. The predominant classification was silicosis, followed by CP, CWP, EWP, FWP, and others; this differed from cases of pneumoconiosis reported in the Xinjiang Uygur Autonomous Region, namely with respect to CWP. The main reason for this discrepancy might be owing to the rapid expansion of the railway system in the $20^{\text {th }}$ century, during which protection for workers was very poor, particularly during mountain blasting. Blasting in mountains produces a lot of dust that contains free silicon dioxide, which caused many mountain workers to develop silicosis. From 1981 to 2012, the number of new pneumoconiosis cases peaked in 1986. However, this was not because of the increasing numbers of mountain workers but rather because silicosis fibrosis caused by the inhalation of free silicon dioxide dust develops slowly and is related to the patients' personal fitness, the amount of inhaled dust, working duration, etc. Some patients might present with respiratory symptoms shortly after inhalation, while others might develop symptoms after a long period. Accordingly, there was substantial variation in the patients' enrollments by year. In 1986, several patients were diagnosed with silicosis during screening for occupational diseases, greatly increasing the number of new cases of pneumoconiosis.

\section{Pneumoconiosis combined with tuberculosis and pleural effusion reported by the Urumqi Railway Bureau}

From 1981 to 2012, among all new cases of pneumoconiosis, there were 226 cases of pneumoconiosis combined with pulmonary tuberculosis including active, suspected, and old tuberculosis; the combination rate was $6.78 \%$, which is less than that reported by Ji et al. (2011). The number of cases of pneumoconiosis combined with tuberculosis peaked twice. The first peak occurred in 1986, which is related to the large number of pneumoconiosis cases diagnosed that year. Meanwhile, the other small peak occurred in 2012. Although the diagnosis of pneumoconiosis decreased significantly after 2000, many patients previously diagnosed with pneumoconiosis gradually developed pulmonary tuberculosis after 2000; this is related to the increasing trend of tuberculosis in Xinjiang in recent years.

In the past 5 years, many clinical cases of pneumoconiosis combined with pleural effusion have been reported, with the majority being transudate rather than exudate. After further diagnosis, patients with suspected tuberculous pleural effusion are administered anti- 
tuberculosis treatment, cases considered inflammatory pleural effusion are administered antiinflammatory treatment, cases considered hypoalbuminemia are administered symptomatic treatment, and cases considered malignant are transferred to oncology departments for further treatment. Pneumoconiosis co-occurs with pleural effusion due to various reasons, including advanced age and diminished immunity; in addition, patients with pulmonary tuberculosis in Xinjiang accounted for the front place domestically. These factors would collectively increase the number of cases of pneumoconiosis combined with pleural effusion.

\section{ACKNOWLEDGMENTS}

The investigation was supported by the professionals in the Center of Disease Prevention and Control of Xinjiang Uygur Autonomous Region, and by the Occupational Disease Prevention Branch, the 5th Affiliated Hospital of Xinjiang Medical University and the Center of Disease Control of Urumqi Railway Bureau. Research supported by the National Natural Science Foundation of China (\#81360416).

\section{REFERENCES}

Bang KM, Attfield MD, Wood JM and Syamlal G (2008). National trends in silicosis mortality in the United States, 19812004. Am. J. Ind. Med. 51: 633-639.

Carneiro AP, Barreto SM, Siqueira AL, Cavariani F, et al. (2006). Continued exposure to silica after diagnosis of silicosis in Brazilian gold miners. Am. J. Ind. Med. 49: 811-818.

Choi BS, Park SY and Lee JO (2010). Current status of pneumoconiosis patients in Korea. J. Korean Med. Sci. 25: S13-S19.

Courtice MN, Lin S and Wang X (2012). An updated review on asbestos and related diseases in China. Int. J. Occup. Environ. Health 18: 247-253.

Hnizdo E and Vallyathan V (2003). Chronic obstructive pulmonary disease due to occupational exposure to silica dust: a review of epidemiological and pathological evidence. Occup. Environ. Med. 60: 237-243.

Ji FL, Chen L and Wang HL (2011). Epidemiological analysis on newly diagnosed cases of pneumoconiosis in Qingdao City, 1988-2009. Preventive Med. Tribune 6: 039.

Kauppinen T, Toikkanen J, Pedersen D, Young R, et al. (2000). Occupational exposure to carcinogens in the European Union. Occup. Environ. Med. 57: 10-18.

Laney AS, Petsonk EL and Attfield MD (2010). Pneumoconiosis among underground bituminous coal miners in the United States: is silicosis becoming more frequent? Occup. Environ. Med. 67: 652-656.

Li T, Li CT and Wang HQ (2010). Review of occupational hazard census and large-scale surveys in sixty years in China. Zhonghua Lao Dong Wei Sheng Zhi Ye Bing Za Zhi. 28: 805-809.

Linch KD, Miller WE, Althouse RB, Groce DW, et al. (1998). Surveillance of respirable crystalline silica dust using OSHA compliance data (1979-1995). Am. J. Ind. Med. 34: 547-558.

Madl AK, Donovan EP, Gaffney SH, McKinley MA, et al. (2008). State-of-the-science review of the occupational health hazards of crystalline silica in abrasive blasting operations and related requirements for respiratory protection. $J$. Toxicol. Environ. Health B Crit. Rev. 11: 548-608.

Mazurek JM and Attfield MD (2008). Silicosis mortality among young adults in the United States, 1968-2004. Am. J. Ind. Med. 51: 568-578.

Mo J, Wang L, Au W and Su M (2014). Prevalence of coal workers' pneumoconiosis in China: a systematic analysis of 2001-2011 studies. Int. J. Hyg. Environ. Health 217: 46-51.

Nasrullah M, Mazurek JM, Wood JM, Bang KM, et al. (2011). Silicosis mortality with respiratory tuberculosis in the United States, 1968-2006. Am. J. Epidemiol. 174: 839-848.

Nelson G (2013). Occupational respiratory diseases in the South African mining industry. Glob. Health Action 6: 19520.

Nelson G, Girdler-Brown B, Ndlovu N and Murray J (2010). Three decades of silicosis: disease trends at autopsy in South African gold miners. Environ. Health Perspect. 118: 421-426.

$\mathrm{Ou} \mathrm{W} \mathrm{(2011).} \mathrm{The} \mathrm{ministry} \mathrm{of} \mathrm{health} \mathrm{of} \mathrm{situation} \mathrm{of} \mathrm{occupational} \mathrm{disease} \mathrm{prevention} \mathrm{and} \mathrm{control} \mathrm{work} \mathrm{throughout} \mathrm{the}$ country in 2010 and 2011 the key work. Safety Health 13: 31. 
Rosenman KD, Reilly MJ and Henneberger PK (2003). Estimating the total number of newly-recognized silicosis cases in the United States. Am. J. Ind. Med. 44: 141-147.

Saiyed HN and Tiwari RR (2004). Occupational health research in India. Ind. Health 42: 141-148.

Seaton A, Legge JS, Henderson J and Kerr KM (1991). Accelerated silicosis in Scottish stonemasons. Lancet 337: 341 344.

Smith DR and Leggat PA (2006). 24 years of pneumoconiosis mortality surveillance in Australia. J. Occup. Health 48: 309-313.

Soutar CA, Hurley JF, Miller BG, Cowie, et al. (2004). Dust concentrations and respiratory risks in coalminers: key risk estimates from the British Pneumoconiosis Field Research. Occup. Environ. Med. 61: 477-481.

Suarthana E, Laney AS, Storey E, Hale JM, et al. (2011). Coal workers' pneumoconiosis in the United States: regional differences 40 years after implementation of the 1969 Federal Coal Mine Health and Safety Act. Occup. Environ. Med. 68: 908-913.

Wang DY and Wang XH (2010). The epidemiology investigations of pneumoconiosis Xinjiang Urumqi-changji in 19762006. Endemic Disease Rep. J. 25: 46-48.

Zhang M, Wang D, Zheng YD, Du XY, et al. (2013). Analyses on the characteristics and the trends of pneumoconiosis notified between 1997 and 2009, in China. Zhong hua Lao Dong Wei Sheng ZhiYe Bing Za Zhi. 31: 321-334. 